\title{
Plant Growth Inhibitors Produced by Fungi
}

\section{Part I. Isolation and Identification of Penicillic Acid and Dihydropenicillic Acid}

\author{
By Takeshi Sassa, Susumu Hayakari, Michimasa Ikeda \\ and Yukichi MIURA \\ Department of Agricultural Chemistry, Yamagata University, \\ Tsuruoka, Yamagata, Japan \\ Received April 24, 1971
}

In our screening program in search of new plant growth inhibitors among fungal metabolities, we found that the culture filtrate of a fungus, 487-16 (genus and species unidentified), inhibited the growth of rice seedlings. An active principle was isolated, and was identified as penicillic acid. In addition, a new fungal metabolite dihydropenicillic acid was isolated as a major product. We report the isolation and identification of penicillic acid and dihydropenicillic acid.

The fungus was aerobically grown at $28^{\circ} \mathrm{C}$ for 4 days in a natural medium containing peptone and corn steep liquor. The culture filtrate (10 liters) was acidified to $\mathrm{pH} 3.0$ with dilute sulfuric acid followed by extraction with ethyl acetate. The ethyl acetate extracts were concentrated and extracted several times with 3\% sodium bicarbonate solution. Concentration of the ethyl acetate solution produced crystals which were recrystallized from ethyl acetate-hexane to give colorless needles (I, $1100 \mathrm{mg}$ ), $\mathrm{mp} 84^{\circ} \mathrm{C}$. This was inactive to a rice seedling test. Each of the sodium bicarbonate extracts was acidified to $\mathrm{pH} 3.0$ with dilute sulfuric acid, then extracted with ethyl acetate. Biologically active ethyl acetate extracts were combined and concentrated in vacuo to afford active crystals. Recrystallization from ethyl acetate-hexane gave colorless needles (II, $900 \mathrm{mg}$ ), $\mathrm{mp} 86^{\circ} \mathrm{C}$. II inhibited root elongation at a concentration of $300 \mathrm{ppm}$ in the rice seedling test. Inhibition of root elongation in Chinese cabbage seedlings was observed at a lower concentration.

II exhibited the following spectral properties; $\mathrm{UV} \lambda_{\max }^{\mathrm{H}_{2} \mathrm{O}} \mathrm{m} \mu(\varepsilon): 227(11300), \quad \mathrm{IR} \nu_{\max }^{\mathrm{KBr}} \mathrm{cm}^{-1}$ : $3270,1728,1643,1352,1223,909,811$. II was identified as penicillic acid by its physicochemical and spectral properties." The molecular formula of $\mathrm{I}, \mathrm{C}_{8} \mathrm{H}_{12} \mathrm{O}_{4}$, was assigned on the basis of elementary analysis and the mass spectrum. The UV and IR spectra were quite similar to those of II (Fig. 1). It gradually

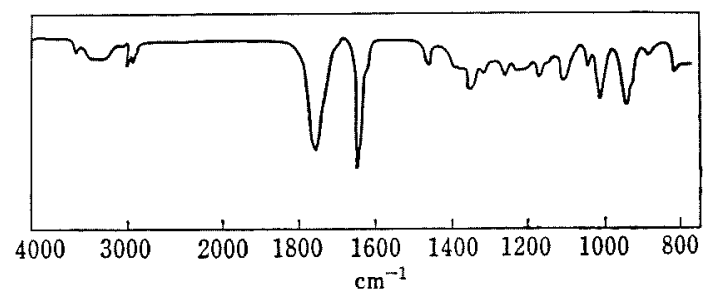

FIG. 1. IR Spectrum of $\mathrm{I}\left(\mathrm{CHCl}_{3}\right.$ solution).

dissolved in sodium bicarbonate solution, indicating that the carbonyl function was a lactol grouping. The presence of a hydroxyl group was revealed by IR and NMR spectra. In the NMR spectrum, signals at 00.88 and

1) J. H. Birkinshaw, A. E. Oxford and H. Raistrick, Biochem. J, 30, 394 (1936); "Antibiotics," Vol. Il, ed. by Y. Sumiki, Tokyo University Press, Tokyo, 1961, p. 762 . 
1.06 (each $3 \mathrm{H}$, doublet, $J=7 \mathrm{cps}$ ), and 2.18 $(1 \mathrm{H}$, septet, $J=7 \mathrm{cps})$ were assigned to an isopropyl group. Other signals, $3.90(3 \mathrm{H}$, singlet) and $5.02(1 \mathrm{H}$, singlet $)$, respectively, were assigned to a methoxy group at $\beta$-position and a vinyl proton at $\alpha$-position in the $\alpha, \beta$-unsaturated lactol. Based on the above results, I is represented by structure 1 . The structure of I could be interpreted by its mass spectrum (Fig. 2) and was confirmed by trans-

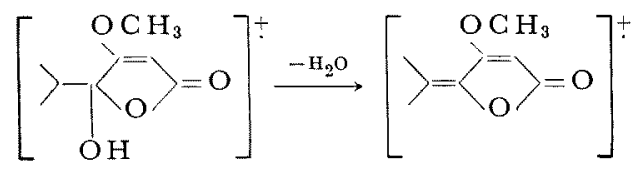

$$
m / e 172 \quad m / e \quad 154
$$

$\downarrow-\mathrm{C}_{3} \mathrm{H}_{7}$

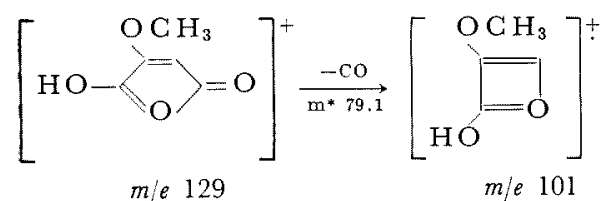

$$
\underset{\mathrm{m}^{*} 47.1}{\stackrel{-\mathrm{CH}_{3} \mathrm{OH}}{\longrightarrow}} m / e 69
$$

FIG. 2. Fragmentation Process of I.

formation of II to I. Hydrogenation of II, on a $5 \%$ palladium-charcoal, afforded colorless needles $\left(\mathrm{mp} 86^{\circ} \mathrm{C}\right.$ ) which were identified as I by their mixed melting point and IR spectrum.<smiles>C=C(C)C(O)(OC)C1=CC(=O)OC1(O)C(C)C</smiles>

Penicillic acid (1) possesses antibacterial and antifungal activity. Recently, antitumor and antiviral properties have been reported." Production of 1 and 2 by the fungus is shown in Fig. 3. It is apparent that 2 was biologically

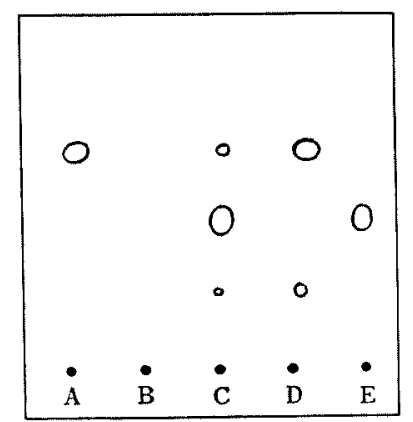

FIG. 3. Thin-layer Chromatogram (Silica gel in ethyl acetate: hexane $=1: 1$ ) Showing Production of I and II in the Culture Filtrate.

A: I, B : 2 days incubation, $\mathrm{C}: 3$ days incubation, $\mathrm{D}: 4$ days incubation, $\mathrm{E}:$ II.

reduced to 1 . The microbial reduction of 2 with antifungal activity to $\mathbf{1}$ is of interest for the detoxication of some biologically active agents.

2) S. Suzuki, T. Kimura, F. Saito and K. Ando, Agr. Biol. Chem., 35, 287 (1971). 